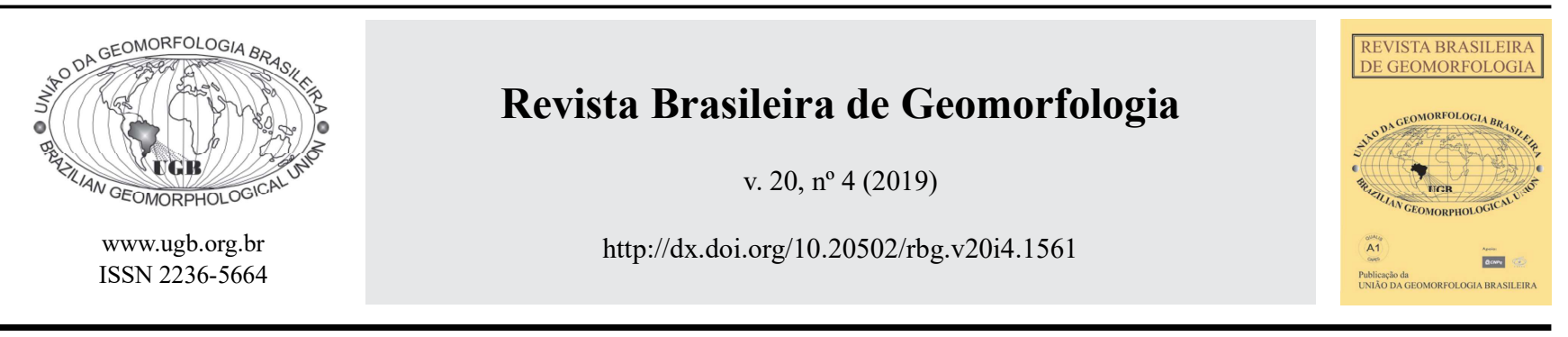

\title{
COMPACTAÇÃO E EROSÃO DE TRILHAS GEOTURÍSTICAS DE PARQUES DO QUADRILÁTERO FERRÍFERO E DA SERRA DO ESPINHAÇO MERIDIONAL
}

\author{
COMPACTING AND EROSION OF GEOTOURIST TRAILS OF \\ THE QUADRILÁTERO FERRÍFERO AND SERRA DO ESPINHAÇO \\ MERIDIONAL PARKS
}

Ricardo Eustáquio Fonseca Filho

Universidade Federal de Ouro Preto

Campus Universitário Morro do Cruzeiro, sn, Ouro Preto, Minas Gerais. CEP 35400-000. Brasil

ORCID: 0000-0001-5804-9120

E-mail: ricardo.fonseca@ufop.edu.br

Angélica Fortes Drummond Chicarino Varajão

Universidade Federal de Ouro Preto

Campus Universitário Morro do Cruzeiro, sn, Ouro Preto, Minas Gerais. CEP 35400-000. Brasil

ORCID: 0000-0002-9930-1801

E-mail: angelica@ufop.edu.br

Paulo de Tarso Amorim Castro

Universidade Federal de Ouro Preto

Campus Universitário Morro do Cruzeiro, sn, Ouro Preto, Minas Gerais. CEP 35400-000. Brasil

ORCID: 0000-0002-7667-0161

E-mail: paulo_de_tarso@ufop.edu.br

\section{Informações sobre o Artigo}

Recebido (Received):

25/05/2019

Aceito (Accepted):

05/09/2019

\section{Palavras-chave:}

Manejo de Trilhas; Penetrometria; Área Seccional Transversal.

Keywords:

Trail Management; Penetrometry; Cross-Sectional Area.

\section{Resumo:}

As trilhas e seu conteúdo, em maior parte os solos, tendem a não serem monitoradas, seja em ambientes urbanos seja natural, como as unidades de conservação. $\mathrm{O}$ uso público por meio do turismo em parques se utiliza das trilhas para usufruto dos atrativos, impactando a superfície (e subsuperfície) dos solos. Pretendeu-se no presente trabalho identificar os níveis de compactação e de erosão dos solos como fatores de alterações ambientais negativas nas trilhas: Pico do Itacolomi - Parque Estadual do Itacolomi, Campo Ferruginoso - Parque Estadual Serra do Rola Moça e Cachoeira da Farofa - Parque Nacional da Serra do Cipó. A metodologia incluiu teste de resistência do solo (compactação) ao penetrômetro de cone com anel dinamométrico e medição da Área Seccional Transversal (erosão). Os resultados demonstram que: o leito das trilhas é, em geral, mais resistente que as margens (áreas não pisoteadas); e há uma correlação diretamente proporcional da litologia com a compactação e a erosão (filitos $>$ quartzitos $>$ canga). A fragilidade dos diferentes substratos (sedimentos de aluvião; quartzitos e filitos; e canga dos 
campos rupestres hematíticos) somada ao pisoteio sem monitoramento pode aumentar a degradação das trilhas, sugerindo-se revisão das normas de visitação.

\begin{abstract}
:
Trails and their elements, especially soils, tend not to be monitored, whether in urban or natural environments such as protected natural areas. Through tourism in parks, the public uses the trails to access the attractions, thus affecting the surface (and subsurface) of the soils. The aim of this study was to identify soil compaction and erosion levels as negative environmental changes on the trails. We focused on the Itacolomi Peak ("Itacolomi" State Park), the Ferruginous Field ("Serra do Rola-Moça" State Park), and the "Farofa" Waterfall ("Serra do Cipó" National Park). The research methodology included a soil resistance test (compaction) on the cone penetrometer using a dynamometric ring and a measurement of the Transversal Sectional Area (erosion). The results demonstrate that the bed of the tracks is, generally, more resistant than the margins (areas not trampled) and that there is a directly proportional correlation of lithology with compaction and erosion (alluvial sediments, quartzites, iron ore deposits). The fragility of the different substrates (alluvial sediments, quartzites and phyllites, and iron ore deposits of the hematite rupestrian fields), in addition to unmonitored trampling, can increase the degradation of the trails. This implies that the rules for tourist trails should be revised.
\end{abstract}

\section{Introdução}

O desenvolvimento da humanidade se deu com o uso e ocupação do espaço. A história dos solos como meio de deslocamento adquire assim novo status: de meio de produção. No entanto, devido aos impactos no solo, abordagens conservacionistas surgiram (FROSSARD $e t$ al., 2006) tais como: estudos de manejo de trilhas com nomenclaturas e parâmetros diversos do ambiente, dos visitantes e de gestão (CLARK \& STANKEY, 1979; STANKEY et al., 1985; LIDDLE, 1997).

Ambiente propício para conservação do solo e manejo das trilhas, as áreas protegidas a exemplo dos parques são áreas-modelo para coleta de dados que, por um lado protegem a área visitada, e por outro, podem ser utilizadas como parâmetros para áreas mais antropizadas (e.g. urbanas).

Todavia poderiam os parques serem mais impactados quanto áreas externas aos mesmos? Pesquisas em áreas protegidas de diversos tipos, biomas e países demonstram que pisoteio na vegetação (MAGRO, 1995), exposição do solo (NORRISH, 2011), compactação (BALL et al., 1997), empoçamento (FIGUEIREDO et al., 2010b), escoamento superficial (FEOLA et al., 2008), erosão (MARION, WIMPEY, 2017), trilhas paralelas/atalhos (LADEIRA, 2005), quebra de galhos (PICKERING et al., 2010), pichação, quebra e coleta de rochas (GRAY, 2005), pisoteio e coleta de plantas (COLE, 2004), poluição sonora (PIJANOWSKI et al., 2011), geração de resíduos (BUCKLEY, 2004), dentre outros são bastante comuns.
Essas alterações ambientais, não somente na biodiversidade (WILSON, 1988), mas também na geodiversidade (GRAY, 2004), são passíveis de reverter o princípio fundamental dos parques por um lado e visitação com fins de conservação por outro, ou seja, de conservação para degradação. Haja vista que parte da visitação se dá em trilhas, elencar indicadores de qualidade física do solo que possam ser comparados e prever danos maiores ao habitat e possivelmente aos visitantes - acidentes, educação ambiental etc. -, pode e deve ser fomentado por gestores com embasamento em pesquisas científicas.

Um dos tipos de indicadores são os chamados "geoindicadores" (BERNER \& IAMS, 1996) "qualidade do solo" (KARLEN et al., 1997) e "erosão do solo e de sedimentos" (IUGS, 2017a), que demonstram processos naturais do balanço morfogênese-pedogênese que podem ser potencializados pela visitação sem consideração à fragilidade do substrato: afloramento rochoso, solo exposto ou com cobertura vegetal.

As paisagens de Minas Gerais, do Quadrilátero Ferrífero (QFe) e da Serra do Espinhaço Meridional (SdEM) são retratadas e descritas por viajantes desde o séc. XIX quanto aos minerais, flora e ofícios das sociedades percorridas (SAINT-HILLAIRE, 1830; ESCHWEGE, 1833). A geodiversidade (SHINZATO et al., 2008; MACHADO \& SILVA, 2010) dessas regiões mineiras é premente nas unidades de conservação (UC) Parque Estadual do Itacolomi (Peit), Parque Estadual Serra do Rola-Moça (PESRM) e Parque Nacional da Serra do Cipó (PNSC). Motivo pelo qual Peit e PESRM constituem parte do patrimônio geológico do Geopar- 
que do Quadrilátero Ferrífero (RUCHKYS, 2007), continuação sul da Serra do Espinhaço (ROESER \& ROESER, 2010). A maior parte dos atrativos mais visitados destes parques, como picos, campo ferruginoso e cachoeiras respectivamente, são alcançados por trilhas, que notadamente demonstram estar, em sua grande parte, impactadas. Para a conservação desses ambientes naturais é necessário seu monitoramento, considerando que são "prioritária para a conservação da biodiversidade" (MINAS GERAIS, 2012) e "áreas restritivas para a geodiversidade" (MACHADO \& SILVA, 2010).

Desta forma o objetivo do presente trabalho foi o de identificar os níveis de compactação e de erosão dos solos como fatores de alterações ambientais negativos de três trilhas de uso público de atrativos com alta visitação no QFe e SdEM: Trilha Pico do Itacolomi (PI) - Peit, Trilha Campo Ferruginoso (CFe) - PESRM e Trilha Cachoeira da Farofa (CFa) - PNSC.

\section{Caracterização da área de estudo}

O Peit (Figura 1), localizado na região sudeste do Quadrilátero Ferrífero, em Mariana e Ouro Preto, com área de 7.543 ha, foi criado em 1967 (MINAS GERAIS, 2007a). Tem como unidades principais o Grupo Itacolomi que é composto sobremaneira por meta-quartzo-arenito, com camadas de metapelitos, e o Grupo Sabará, que se constitui em sua maior parte por rochas metavulcânicas e xistos verdes (DORR, 1969; ALKMIM \& MARSHAK, 1998). Geomorfologicamente é controlado lito-estruturalmente (VARAJÃO, 1988), com três patamares identificáveis (MINAS GERAIS, 2007a): 1) O patamar superior, representado pelas cumeeiras dos meta-quartzo-arenitos da Serra do Itacolomi e seu cume, o Pico do Itacolomi a $1.772 \mathrm{~m}$; 2) um patamar médio constituído quase que exclusivamente por estas mesmas rochas com intercalações de metapelitos; e 3) um patamar inferior que abrange os metapelitos. No relatório do meio físico do Plano de Manejo do Peit (NALINI et al., 2006) a área deste estudo é denominada Unidade Ecomorfológica (UE) Itacolomi, que é modelada sobre meta-quartzo-arenitos e metapelitos. Os solos são, em geral, rasos, arenosos, pobres em nutrientes e jovens (Cambissolos e Neossolos).

$\mathrm{O}$ acesso ao Peit se dá, partindo-se de Belo Horizonte pela BR-040, BR-356 e estradas de terra até a Fazenda do Manso e, em seguida do Morro do Cachorro, onde a trilha PI se inicia numa bifurcação para a Lagoa Seca. A trilha amostrada (Figura 1), localizada sobre as duas unidades acima descritas e nos patamares superior e médio, é linear, com cerca de $2.225 \mathrm{~m}$ de extensão, tem altimetria aproximada entre as cotas de $1.592 \mathrm{me} 1.692$ m. É uma das trilhas mais utilizadas na modalidade hiking (caminhada sem pernoite) na UC, e considerada como trilha oficial para o principal atrativo do Parque (o Pico do Itacolomi) - o acesso pelas trilhas do Calaes e da Serrinha não tem controle da visitação (portarias). não há estudos de capacidade de carga turística $(\mathrm{CCT})^{1}$ para a trilha, apesar: a) dos diversos estudos de endemismo de anfíbios e plantas na área da Lagoa Seca - que se localiza ao longo da trilha - devido às variações hídricas de acordo com as estação chuvosa; e b) essa trilha estar inserida na Zona Primitiva ${ }^{2}$ (MINAS GERAIS, 2007a).

O PESRM (Figura 2), localizado a Noroeste do Quadrilátero Ferrífero, nos municípios de Belo Horizonte, Brumadinho, Ibirité e Nova Lima, tem cerca de 3.940 ha e foi criado em 1994 (MINAS GERAIS, 2007b). Tem como unidade principal o grupo Itabira (DORR, 1969), representado por itabiritos e dolomitos ferruginosos das formações Cauê e Gandarela, respectivamente. A geomorfologia do PESRM (MINAS GERAIS, 2007b) é caracterizada pela junção das megaestruturas que constituem as Serras do Curral e da Moeda, apresentando um relevo dividido em compartimentos com controle lito-estrutural. No que se refere à Escarpa Norte da Serra do Curral, também designada Homoclinal da Serra do Curral, três feições de relevo a caracterizam: 1) no terço superior os itabiritos cobertos por couraças com cristas paralelas e ravinas - onde se localiza a trilha, objeto deste estudo; 2) na porção intermediária rochas dolomíticas com patamares aplainados; e 3) no terço inferior, filitos e quartzitos com colinas de baixa declividade. Os solos são ricos em óxidos de ferro, rasos, pouco férteis, pedregosos e jovens (Plintossolos, Cambissolos e Neossolos) (CARVALHO FILHO et al., 2010).

\footnotetext{
${ }^{1}$ A capacidade de carga turística, desenvolvida por Wolters (1989) é uma metodologia de capacidade de carga ambiental relacionada à capacidade biofísica e social do entorno, com relação à atividade turística e seu desenvolvimento, representado pelo máximo nível de uso por visitantes que uma área pode se manter. Considera, dentre outros fatores de correção: a erodibilidade, ou seja, a vulnerabilidade ou suscetibilidade à erosão (LAL, 1988).

${ }^{2}$ Zona Primitiva "é aquela cujo objetivo é a preservação do ambiente natural e ao mesmo tempo, a promoção de atividades de pesquisa científica e educação ambiental" (IBAMA, 2002).
} 


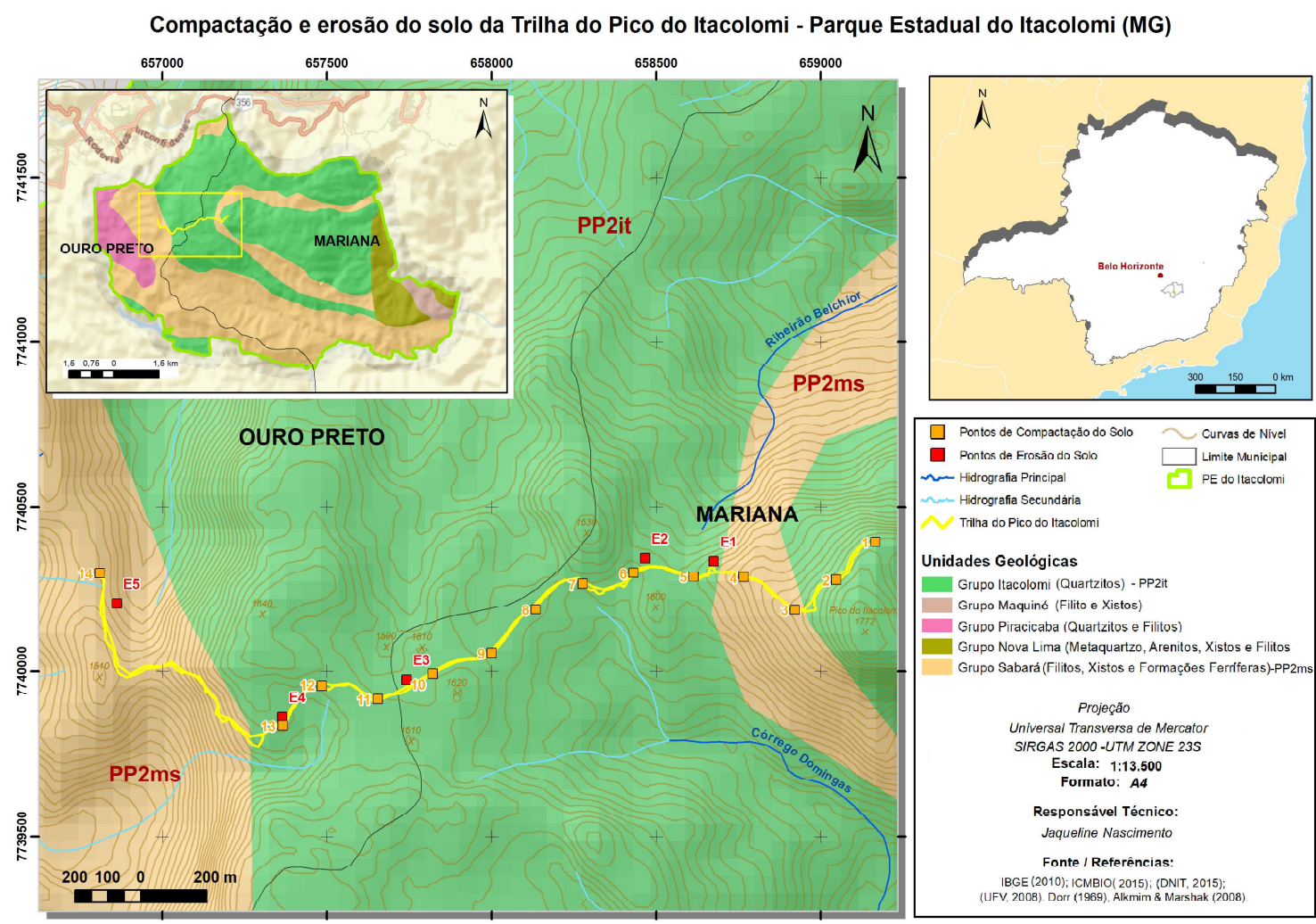

Figura 1 - Localização pontos de compactação e de erosão da Trilha do Pico do Itacolomi, Parque Estadual do Itacolomi, Mariana e Ouro Preto (MG).

O acesso ao PESRM se dá pela BR-040, Jardim Canadá (Nova Lima) e estrada para Casa Branca (distrito de Brumadinho). A trilha denominada "Campo Ferruginoso",, $\mathrm{CFe}$, (Figura 2) se situa sobre cangas e itabiritos das formações Cauê e Gandarela, é linear, com cerca de $2.583 \mathrm{~m}$ de extensão e altimetria aproximada entre as cotas de $1.396 \mathrm{~m}$ e $1.497 \mathrm{~m}$. Ela é considerada como área de Refúgio Ecológico, pela riqueza de espécies, incluindo endêmicas (VINCENT, 2004). O Plano de Manejo define a CCT em 24 pessoas/dias em grupos de até 6 pessoas - a menor capacidade de carga das trilhas do Parque do Rola-Moça. O que confirma sua fragilidade, validada pela proibição de atividades de turismo ${ }^{4}$.

O PNSC (Figura 3), localizado na porção sul da Serra do Espinhaço, nos municípios de Itambé do Mato Dentro, Jaboticatubas, Morro do Pilar, Nova União e Santana do Riacho, tem cerca 31.640 ha e foi criado em 1984 (MINAS GERAIS, 2007b). Compreende rochas do embasamento pré-Espinhaço, coberturas do Supergrupo Espinhaço (Proterozóico Médio), Grupos
Macaúbas e Bambuí (Proterozóico Superior) e depósitos do Quaternário (OLIVEIRA et al., 1997). O relevo regional da Serra do Cipó possui direção NNW-SSE, sendo a morfologia caracterizada por escarpas e patamares de diversas dimensões, superfícies embutidas e vales ortoclinais (GONTIJO, 1993; PELOSO, 2009). Ross (1996) classifica a Serra do Cipó como Planaltos e Serras do Atlântico Leste-Sudeste. Alguns autores (e.g. GONTIJO, 1993; ICMBIO, 2009; FELIPPE et al., 2012) definiram paisagens, às vezes denominadas Unidades Geomorfológicas, ou compartimentos morfológicos para a região. Destacam-se: na borda oeste da Serra do Espinhaço as Escarpas Escalonadas; e na área de estudo (PNSC) as Planícies Fluviais dos Rios Mascates (onde se encontra a trilha deste estudo), Bocaina e Cipó e Terraços da Depressão do Rio das Velhas. Os solos são Neossolos e Cambissolos (ICMBIO, 2009) e Espodossolos (FONSECA FILHO, 2012), portanto, pobres, rasos e arenosos, resultantes, assim como nas outras UC, do material de origem e relevo.

\footnotetext{
${ }^{3}$ No Plano de Manejo do Parque Estadual Serra do Rola-Moça (MINAS GERAIS, 2007b) a trilha é maior, agregando outros dois atrativos, o Mirante Três Pedras e o Mirante Planeta. No entanto, no presente trabalho se considerou somente o trecho Centro de Visitantes-Campo Ferruginoso.

${ }^{4}$ Embora se constatou nos trabalhos de campo presença de antenas e redes de energia elétrica, ruinas de guarita de monitoramento abandonada, resquícios de materiais de construção e acesso por jipes e motociclistas trilheiros, gado, bem como transeuntes.
} 


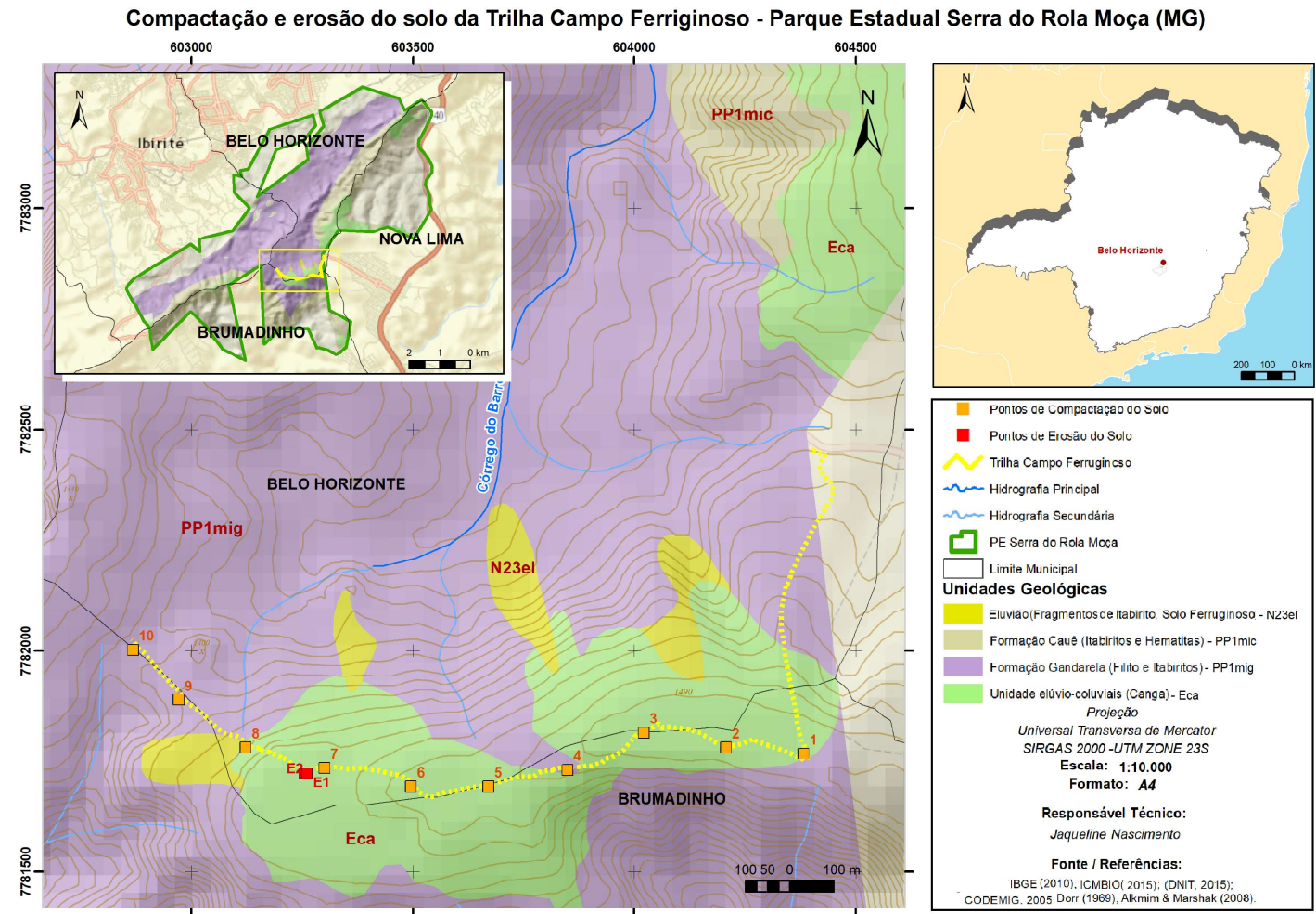

Figura 2 - Localização pontos de compactação e de erosão da Trilha Campo Ferruginoso, Parque Estadual Serra do Rola-Moça, Belo Horizonte e Brumadinho (MG).

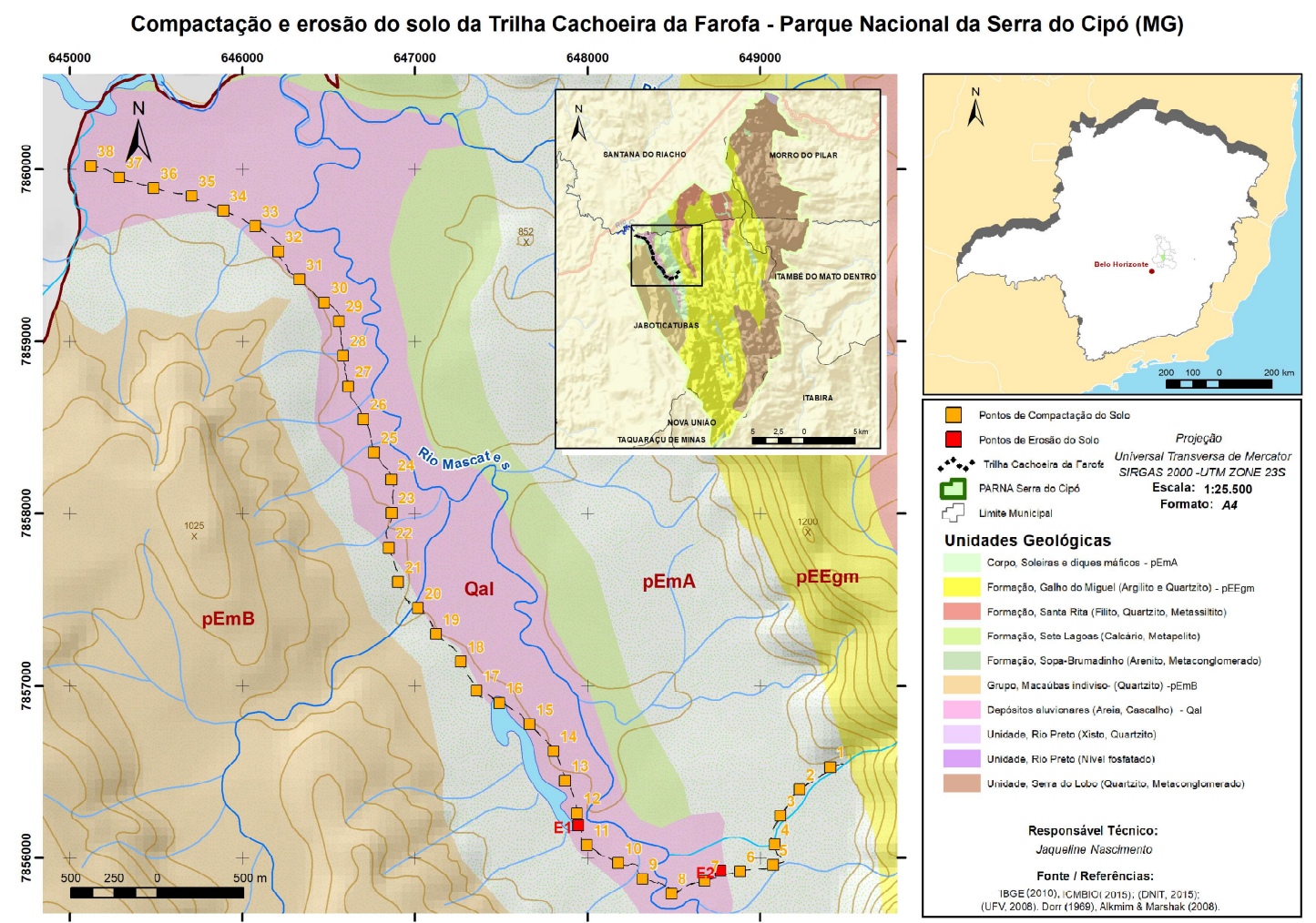

Figura 3 - Localização pontos de compactação e de erosão da Trilha Cachoeira da Farofa, Parque Nacional da Serra do Cipó, Santana do Riacho (MG). 
O acesso ao PNSC se dá, partindo-se de Belo Horizonte pela MG-010 e por estrada de terra na entrada de Santana do Riacho (MG) até a portaria Areias, sede do Parque. A trilha CFa (Figura 3) localiza-se no vale do Mascates, entre as Serras da Bandeirinhas e Confins e tem como substrato sedimentos do Quaternário e quartzitos do Grupo Macaúbas (SILVA et al., 2007). Trata-se de uma trilha linear com cerca de $8.973 \mathrm{~m}$ de extensão e altimetria aproximada entre as cotas de $796 \mathrm{~m}$ e 826 m. É a trilha mais utilizada do Parque, nas modalidades hiking e ciclismo. Em seu zoneamento está na Zona de Recuperação (ICMBIO, 2009), considerada "provisória cujo objetivo é a restauração das áreas degradadas", pela minimização da degradação com a capacidade de carga de 120 pessoas/dia.

Para as três UC o clima é tropical de altitude, sendo Cwa e Cwb no Peit, Cwa no PESRM e Cwb no PNSC, com verões quentes e úmidos e invernos frios e secos. A vegetação é de Cerrado e Mata Atlântica, com presença de fitofisionomias de campos rupestres nas áreas mais elevadas. A hidrografia é composta de rica rede de drenagem, sendo as Bacias Hidrográficas do São Francisco (Peit, PESRM e PNSC) e Doce (Peit).

\section{Materiais e Métodos}

A metodologia se deu por revisão de literatura em escritório e coleta de dados em campo: resistência superficial do solo (penetrometria) e erosão (Área Seccional Transversal - AST).

A escolha das trilhas se deu por: maior visitação do PNSC ao atrativo Cachoeira da Farofa; o atrativo Pico do Itacolomi ser o mais procurado por visitantes; e pelo Campo Ferruginoso no PESRM ser considerada uma área de Refúgio Ecológico com espécies endêmicas.

Através da medição da resistência do solo à penetração pode-se analisar alterações ocorridas nas propriedades físicas do solo quanto à compactação. Utilizando-se o penetrômetro com anel dinamométrico Geotester ${ }^{\mathbb{B}}$ ST-308 (SOLOTEST, 2011) aplicou-se três medições no leito e bordas (esquerda e direita) em cada ponto. Para a seleção dos pontos para as medições foi observada a distância de $200 \mathrm{~m}$ a partir dos atrativos (CFa e PI) até o início da trilha; e no caso do CFe o mesmo distanciamento no topo de morro (não se considerou a estrada de acesso a partir do Centro de Visitantes). Para cada uma das três medições (leito e margens esquerda e direita) tabulou-se no software Microsoft ${ }^{\mathbb{B}}$ Office Excel 2013 chegando-se a uma média para cada ponto amostrado.

Na medição da erosão nas trilhas em estudo do Peit, PESRM e PNSC utilizou-se o método AST (HELGATH, 1975), sendo: medição da largura da trilha nos pontos monitorados; instalação de estacas de madeira nas extremidades transversais do ponto monitorado do leito da trilha; extensão de linha presa entre os dois piquetes (transecto), confirmando-se a horizontalidade com nível ("bolhar"); medição do intervalo da linha horizontal esticada através de trena; e medição vertical da distância entre o solo (superfície da trilha) e a linha horizontal em intervalo de $10 \mathrm{~cm}$. Após a coleta dos dados foi aplicada a fórmula de Leonard \& Whitney (1977):

$$
\mathrm{A}=\frac{\mathrm{V}_{1}+\mathrm{V}_{2}}{2}+\frac{\mathrm{V}_{2}+\mathrm{V}_{3}}{2}+\frac{\mathrm{V}_{\mathrm{n}}+\mathrm{V}_{\mathrm{n}+1}}{2} \times \mathrm{D}
$$

sendo: $\mathbf{A}=$ Área Seccional Transversal; $\mathbf{V}=$ medida das distâncias verticais em $\mathrm{cm} ; \mathbf{e} \mathbf{D}=$ intervalo entre as medidas verticais na linha horizontal estendida.

A escolha dos pontos de erosão em campo considerou a observação da erosão, identificada em trechos com maior declividade, empoçamentos e exposição de raízes. Já o período de medições considerou estações secas e chuvosas, sendo: julho/2013, dezembro/2014, janeiro/2015 e fevereiro/2016 (Peit e PESRM); e agosto/2013, novembro/2014, março/2015 e março/2016 (PNSC).

\section{Referencial Teórico}

Os geoindicadores "são medidas de superfície, ou próximos da superfície, de fenômenos e processos geológicos que variam significativamente no período de 100 anos ou menos e que provêm informações para avaliações ambientais" (BERGER \& IAMS, 1996). Dentre os 27 geoindicadores estabelecidos pela União Internacional de Ciências Geológicas (IUGS) o geoindicador "qualidade do solo" é fortemente influenciado pelas forças da natureza enquanto a pressão humana pode influenciar aquele e a "erosão do solo e de sedimentos" (BERGER, 1997). Eles definem condições, causas, efeitos e implicações, que podem ser utilizadas na conservação e na gestão por exemplo. 
O geoindicador qualidade do solo é "a capacidade do solo de funcionar" (KARLEN et al., 1997). Esta visão, originária de pesquisas agrícolas, demonstra sua relação com a produtividade. O método de medição da qualidade e erosão do solo (IUGS, 2017a, 2017b) inclui descrições e parâmetros físicos.

A compactação do solo é a diminuição do volume do solo ocasionada por compressão, causando rearranjamento mais denso das partículas do solo (CURI, 1993), podendo, assim, diminuir a qualidade do solo para fins como, controle de erosão, agricultura, recarga de água etc. A suscetibilidade à compactação depende de fatores naturais e antrópicos, tais como: textura do solo, regime hídrico, propriedades químicas, biológicas e arranjos e tipos de horizontes; e uso e ocupação do solo (DUIKER, 2004) respectivamente.

A erosão é um processo natural que transforma a paisagem em função do tempo (CURI, 1993). Outras características e propriedades da erosão, bem como fatores similares à compactação podem influenciar a magnitude e intensidade do fenômeno, por exemplo: textura, porosidade (GUERRA \& BOTELHO, 1996); e relevo, litologia e clima (THORNES, 2011). É considerada no presente trabalho a erosão por água, de escoamento superficial, do tipo laminar (LAL, 1990), mas que pode evoluir para em sulcos, ravinas e voçorocas ${ }^{5}$.

A julgar pela pressão antrópica como aceleração de processos naturais, o turismo gera também impactos negativos, como ambientais (SWARBROOKE, 2002) e sociais (KRIPPENDORF, 2000). O olhar pelo geoturismo, como um novo segmento do turismo (NASCIMENTO et al., 2007) pode ser importante para o monitoramento e planejamento da visitação aos atrativos abióticos in situ, chamados de "geossítios", como solos e trilhas. Para Hose (1995) geoturismo é "provisão de serviços e facilidades interpretativas no sentido de possibilitar aos turistas a compreensão e aquisição de conhecimentos de um sítio geológico e geomorfológico ao invés da simples apreciação estética".
Para Follmann et al. (2010) as trilhas interpretativas são instrumentos de geoturismo. Ostanello et al. (2013), Oliveira (2016) e Brito (2015) consideraram as trilhas como parte do geoturismo do Peit, PERSM e PNSC respectivamente. De acordo com a Associação Brasileira de Normas Técnicas trilha é uma "via estreita, usualmente não-pavimentada e intransitável para veículos de passeio" (ABNT, 2008), logo as estradas não são trilhas. Aplicando-se a definição da norma ("trânsito de veículos de passeio") pode-se afirmar que a trilha PI é $100 \%$ trilha, a trilha $\mathrm{CFe} 0 \%$ e a trilha $\mathrm{CFa}$ cerca de $25 \%$. Entretanto é preciso coletar e analisar dados das áreas de estudo para as possíveis correlações uso público (em especial turismo) x conservação/degradação.

\section{Resultados}

\section{Resistência do Solo}

Os 61 pontos analisados se dividiram em: 13 na trilha $\mathrm{PI}$ (Figura 1), 10 na trilha $\mathrm{CFe}$ (Figura 2) e 38 na trilha $\mathrm{CFa}$ (Figura3). Ao longo das trilhas amostradas é possível sentir uma certa "dureza" ao se pisar o solo exposto, que varia em trechos, como de sedimentos e nódulos/fragmentos ferruginosos nas trilhas $\mathrm{CFa}$ e $\mathrm{CFe}$, respectivamente. Apesar da percepção o teste de resistência do solo ao impacto de um cone com ponta e anel dinamométrico permite uma leitura das diferentes resistências, ao longo do leito e das respectivas bordas das trilhas.

Em geral as trilhas têm os pontos com maior resistência à penetração no leito, com variação entre as bordas (Tabela 1). O ponto que apresenta maior compactação superficial do solo na trilha PI foi o leito de $\mathrm{C}^{6}{ }^{6}$, com $3.302 \mathrm{kPa}^{7}$ e o com menor a margem esquerda de $\mathrm{C} 7$, com $1.255 \mathrm{kPa}$ (Figura 4A). O ponto 1 se localiza próximo ao Pico do Itacolomi (Figura 5A) e C7 ao lado da Lagoa Seca (Figura 5B), locais em que foram encontrados perfis de solo das classes Cambissolo e Espodossolo respectivamente.

Tabela 1: Localização dos pontos na trilha (leito e margens) de maior resistência à penetração

\begin{tabular}{ccccc}
\hline Trilha/Pontos & Margem esquerda & Leito & Margem direita & Total (Parque) \\
$\boldsymbol{C F a}$ & 9 & 25 & 4 & 38 \\
$\boldsymbol{C F e}$ & 2 & 4 & 4 & 10 \\
$\boldsymbol{P I}$ & 3 & 8 & 2 & 13 \\
Total (localização trilha) & 14 & 37 & 10 & 61 \\
\hline
\end{tabular}

Legenda: CFa (Cachoeira Farofa); CFe (Campo Ferruginoso); PI (Pico do Itacolomi).

${ }^{5}$ Conforme trecho original interditado na trilha CFa (FIGUEIREDO et al., 2010a)

${ }^{6} \mathrm{CX}$ (ponto de Compactação número).

${ }^{7} 1 \mathrm{kPa}$ (quiloPascal) equivale a $1 \mathrm{kgf} / \mathrm{cm}^{2}$ ou $1 \mathrm{bar}$. 


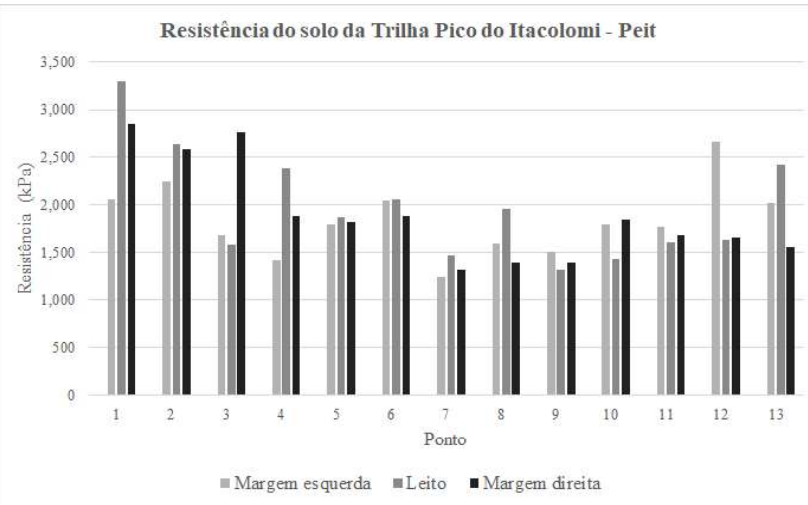

(a)

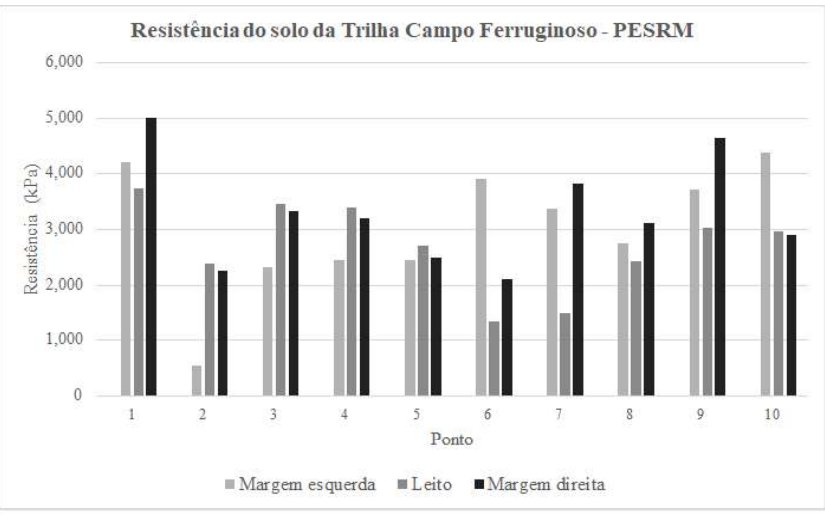

(b)

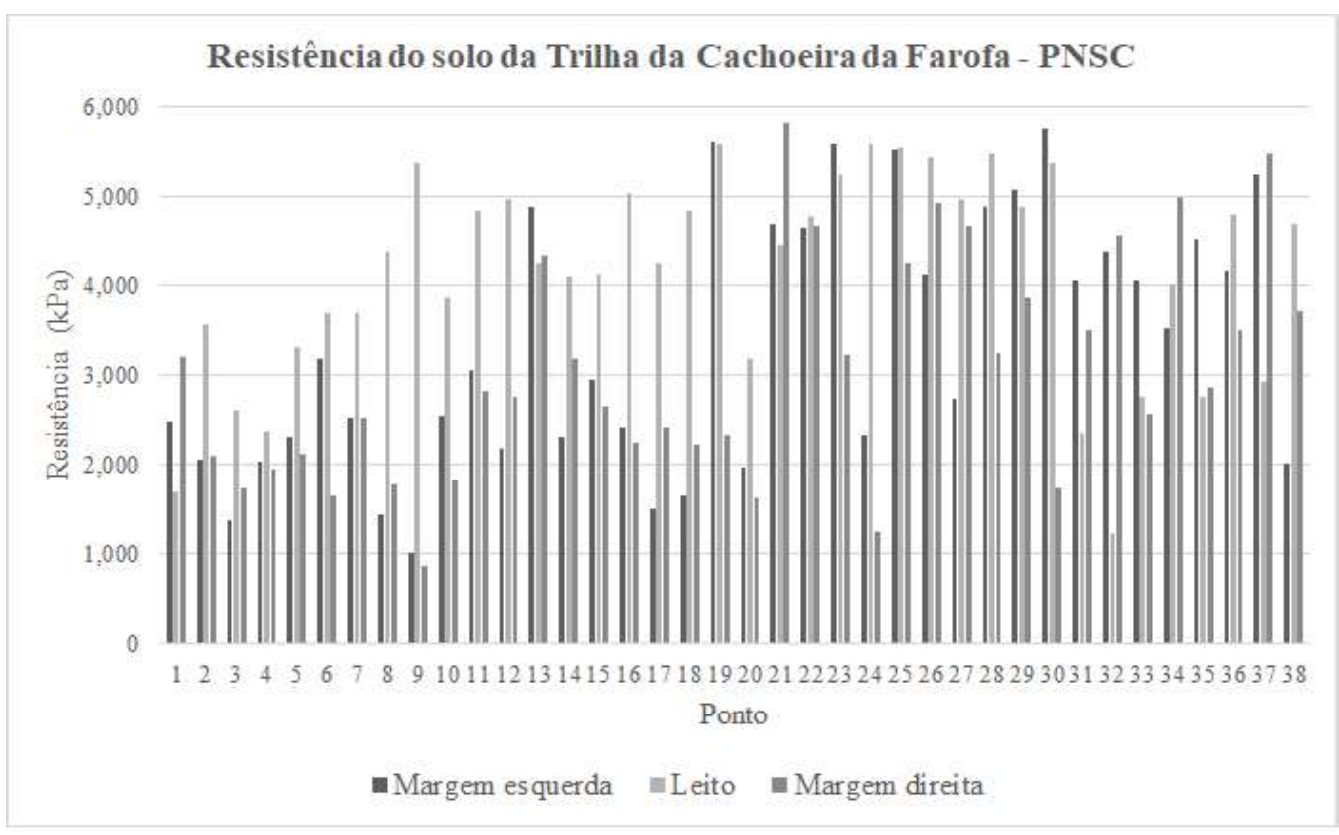

(c)

Figura 4 - Gráficos de resistência à penetração no solo (compactação) A) dos 13 pontos amostrados na Trilha do Pico do Itacolomi, Parque Estadual do Itacolomi, Mariana e Ouro Preto (MG); B) dos 10 pontos amostrados na Trilha Campo Ferruginoso, Parque Estadual Serra do Rola-Moça, Belo Horizonte e Brumadinho (MG); e C) dos 38 pontos amostrados na Trilha Cachoeira da Farofa, Parque Nacional da Serra do Cipó, Brumadinho (MG).

O ponto que apresenta maior compactação superficial do solo na trilha CFe foi o da margem direita de C1 no início da trilha, com $4.998 \mathrm{kPa}$ e o com menor o da margem esquerda de $\mathrm{C} 2$, com $551 \mathrm{kPa}$ (Figura 4B). O ponto de menor resistência no leito da trilha foi C7, com $1.483 \mathrm{kPa}$, localizado no início da descida da trilha, local em que também foi realizada medição da erosão (E2) ${ }^{8}$.

$\mathrm{Na}$ trilha $\mathrm{CFa}$ o ponto cuja medição apresentou maior resistência à penetração foi a margem direita de C21, com 5.820 kPa (Figura 4C) e o com menor a margem direita de $\mathrm{C} 9$, com $878 \mathrm{kPa}$, localizado próximo ao Córrego Mascates e bifurcação para a trilha Cânion Bandeirinhas, setor com maior largura da trilha e presença de sedimentos. No entanto, os pontos com maior e menor compactação aparente no leito da trilha foram os pontos $\mathrm{C} 30$ e C32 respectivamente com $5.386 \mathrm{kPa}$ e $1.227 \mathrm{kPa}$. Nota-se a influência das trilhas paralelas em C30, logo no início da trilha (próximo ao Heliponto e bifurcação para o Rio Cipó) com visitantes andando sob área com solo exposto e com vegetação.

${ }^{8}$ EX (ponto de Erosão número). 


\section{Erosão do Solo}

Todas as medições de erosão do leito principal das trilhas apresentaram perda de solo (maior), e ganho (menor), num balanço de matéria dentro do próprio leito. Dos nove pontos monitorados cinco foram na trilha PI, e dois na $\mathrm{CFa}$ e $\mathrm{CFe}$. Esta relação desproporcional entre comprimento da trilha e número de medições se deve à maior distância do PNSC para a amostragem, além da trilha ter sido exaustivamente monitorada em estudos similares (FIGUEIREDO et al., 2012).

Os trechos das trilhas com maior largura do leito da trilha principal com medição da erosão foram no PNSC, com $310 \mathrm{~cm}$ (E1) e $260 \mathrm{~cm}$ (E2); seguidos pelo PESRM, com $250 \mathrm{~cm}$ (E1) e $220 \mathrm{~cm}$ (E2); e no Peit, 220 cm (E3), $150 \mathrm{~cm}$ (E2), $140 \mathrm{~cm}$ (E1) e $120 \mathrm{~cm}$ (E4 e E5). Nota-se, como exposto anteriormente, o acesso (formal ou não) às trilhas $\mathrm{CFa}$ e PI por veículos motorizados, com larguras correspondentes (trilhas e veículos).

A erosão que evoluiu mais foi E3, no Peit (Figura 5c, Tabela 2), com perda de solo de $3.492 \mathrm{~cm}^{2}$, com exposição de perfil de solo arenoso, Neossolo. Destaque ainda na trilha da UC para E2, cuja declividade maior favoreceu o escoamento superficial retirando o solo e carreando na forma de sedimento. Em E1, E4 e E5, embora houve erosão, se mostraram mais estáveis, em especial a última, única amostragem localizada sob xistos e filitos do Grupo Sabará, enquanto as demais sob quartzitos do Grupo Itacolomi.

As demais perdas de solo (Tabela 2) na trilha PI foram de: $981 \mathrm{~cm}^{2}$ (E2), $535 \mathrm{~cm}^{2}$ (E1), $517 \mathrm{~cm}^{2}$ (E4) e $487 \mathrm{~cm}^{2}$ (E5). Na trilha $\mathrm{CFa}$ as erosões apresentam padrão similar ao encontrado por Gualtieri-Pinto et al. (2008), de perda de solo: $1.803 \mathrm{~cm}^{2}$ (E1) e $567 \mathrm{~cm}^{2}$ (E2). As menores perdas de solo foram na trilha CFe, com $65 \mathrm{~cm}^{2}$ (E1) e $63 \mathrm{~cm}^{2}$ (E2).

\section{Discussão dos Resultados}

O presente trabalho não fez medição da resistência do solo que não no leito e margens das trilhas. Qiang
(2006) por sua vez observou em trilhas do Geopark de Zhangjiajie, na China, que os impactos na dureza do solo chegam à distância de $1 \mathrm{~m}$ a $3 \mathrm{~m}$ da trilha, demonstrando que mesmo que não haja solo exposto ou trilhas paralelas e atalhos, o impacto extrapola a região de pisoteio. $\mathrm{O}$ que vem de encontro aos dados encontrados nas trilhas amostradas, pela resistência à penetração nas margens.

As erosões observadas se encontram em planos inclinados (declives/aclives) das trilhas. Correlação essa evidenciada por Ferreira et al. (2016), que apontaram relação diretamente proporcional da declividade e uso (pisoteio e infraestrutura p.ex.) com a erosão, em trilha da Floresta Nacional de Ritápolis (MG). Entretanto, tal evidência não impede que a erosão ocorra em planos com pouca ou nenhuma declividade, conforme observado por Figueiredo et al. (2010a, 2010b) na trilha CFa, onde o pisoteio influenciou na compactação, propiciando a não infiltração da água no solo e a formação de poças, deslocando o visitante para áreas visíveis e secas. Tal processo causa a formação de trilhas paralelas, desencadeando o processo de compactação-não infiltração-empoçamento, e, consequentemente, gerando um plano declivoso que alavanca a erosão. Rangel (2014) também observou esse comportamento das poças com a compactação e a erosão em trilhas na Área de Proteção Ambiental Cairuçu, Paraty (RJ).

Saraiva (2011) ratifica o pisoteio como fator de compactação e erosão na Trilha dos Escravos, em Ubatuba (SP), enquanto Sena et al. (2014) corroboram, assimilando a suscetibilidade à erosão ao caráter psamítico do solo em trilha no Monumento Geoturístico Serra de São José (MG). Isso foi observado nas trilhas PI e CFa, com maior perda de solo em áreas com Neossolos e solo com textura arenosa. Por outro lado, a trilha $\mathrm{CFe}$ não apresentou empoçamentos que acelerassem a erosão, mas a cimentação em trechos de canga impermeabilizando o solo, contribuíram para a perda de solo.

Tabela 2: Perda de solo dos pontos de erosão monitorado nas trilhas

\begin{tabular}{cccccccccc}
\hline $\begin{array}{c}\text { Ano/Área } \\
\left(\mathbf{c m}^{2}\right) \text { Ponto }\end{array}$ & E1-Peit & E2-Peit & E3-Peit & E4-Peit & E5-Peit & E1-PESRM & E2-PESRM & E1-PNSC & E2-PNSC \\
2013 & 6.955 & 7.465 & 12.247 & 6.332 & 6.730 & 6.755 & 7.470 & 7.452 & 6.909 \\
2014 & 7.255 & 7.828 & 13.990 & 6.515 & 6.875 & 6.765 & 7.480 & 7.829 & 6.982 \\
2015 & 7.357 & 8.197 & 15.191 & 6.596 & 7.037 & 6.798 & 7.533 & 8.413 & 7.177 \\
2016 & 7.490 & 8.446 & 15.739 & 6.849 & 7.217 & 6.820 & 7.543 & 9.255 & 7.486 \\
\hline $\mathbf{A T}\left(\mathbf{c m}^{\mathbf{2}}\right)$ & $\mathbf{5 3 5}$ & $\mathbf{9 8 1}$ & $\mathbf{3 . 4 9 2}$ & $\mathbf{5 1 7}$ & $\mathbf{4 8 7}$ & $\mathbf{6 5}$ & $\mathbf{7 3}$ & $\mathbf{1 . 8 0 3}$ & $\mathbf{5 7 7}$ \\
\hline
\end{tabular}

Legenda: E1 (Erosão 1); Peit (Parque Estadual do Itacolomi); PESRM (Parque Estadual Serra do Rola-Moça); PNSC (Parque Nacional Serra do Cipó); AT (Área Total) = área medida em 2016-área medida 2013 = perda total de solo no período $\left(\mathrm{cm}^{2}\right)$. 
Fonseca Filho R. E. et al.

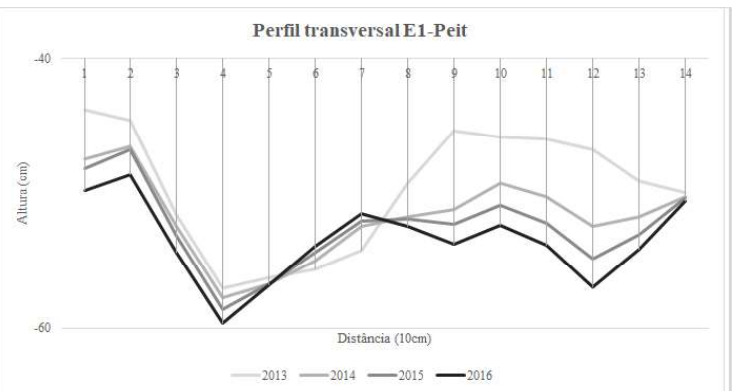

(a)

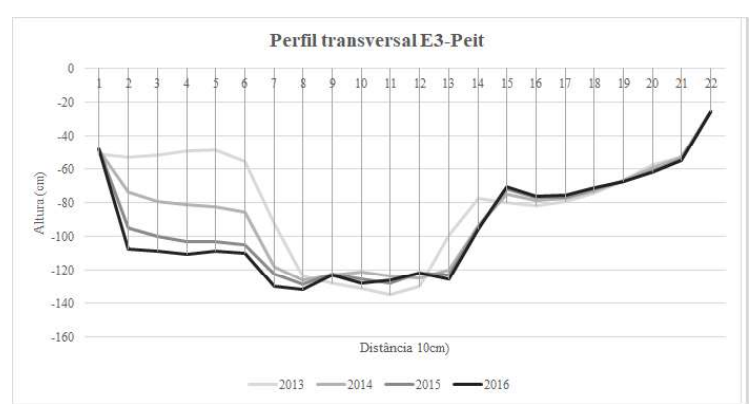

(c)

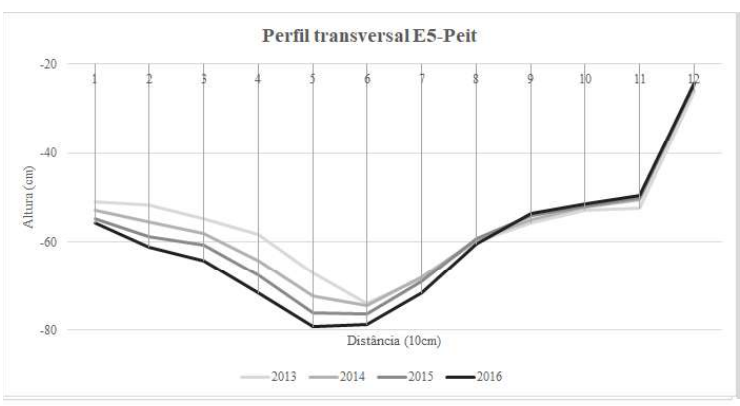

(e)

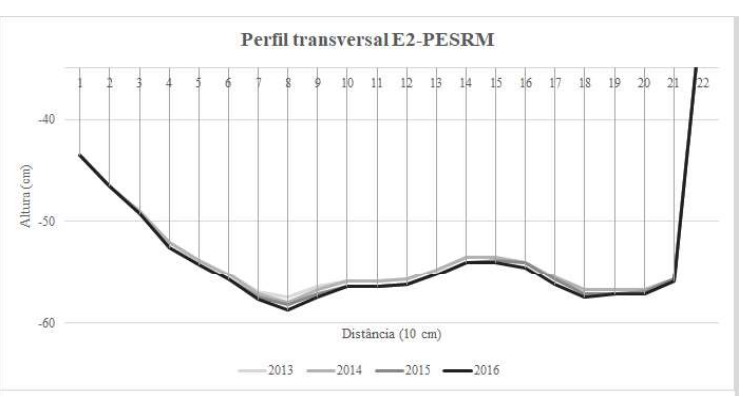

(g)

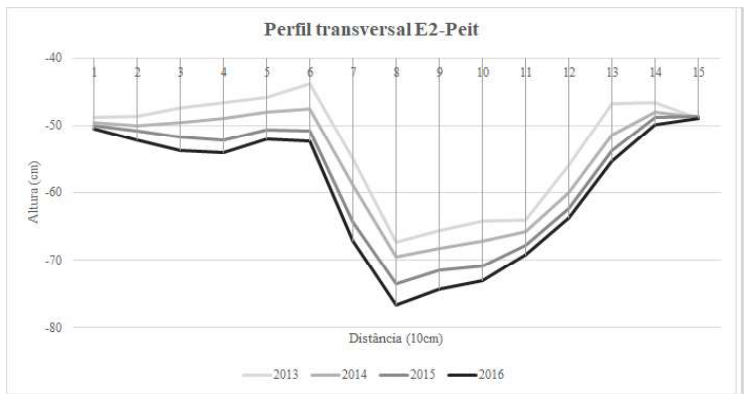

(b)

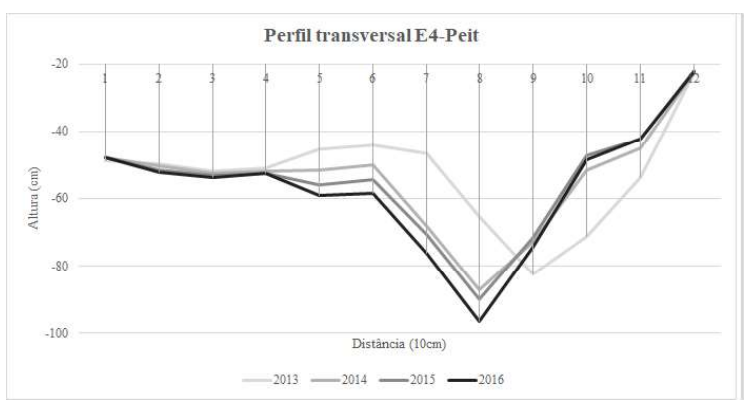

(d)

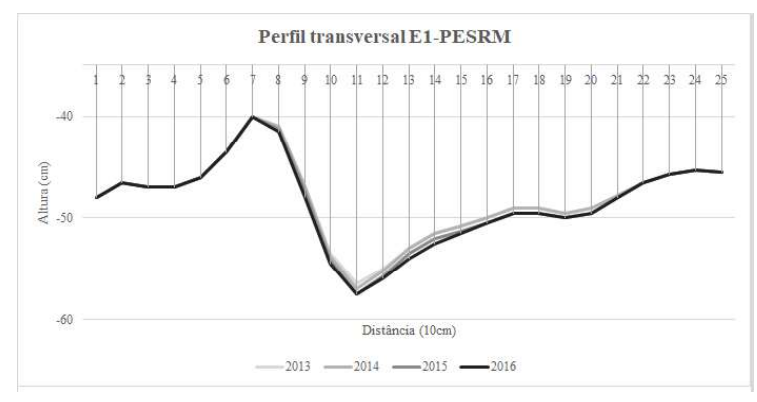

(f)

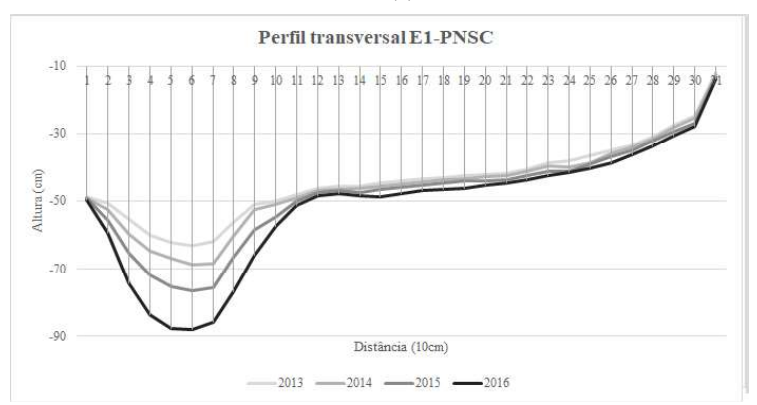

(h)

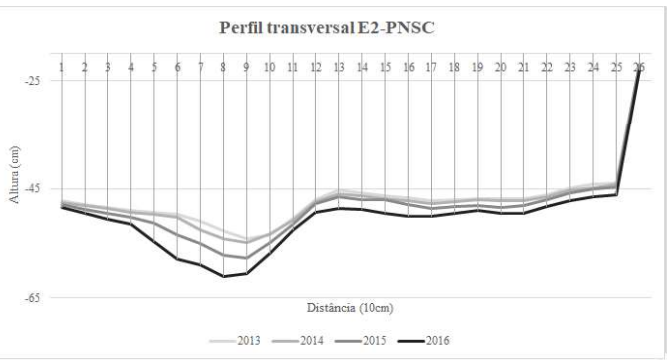

(i)

Figura 5 - A) Gráficos das medições do ponto E1 da erosão monitorada na trilha do Pico do Itacolomi- Peit; B) ponto E2-Peit; C) ponto E3Peit; D) ponto E4-Peit; E) ponto E5-Peit; F) Gráficos das medições do ponto E1 da erosão monitorada na trilha Cachoeira da Farofa-PNSC; G) ponto E2-PNSC; H) Gráficos das medições do ponto E1 da erosão monitorada na trilha Campo Ferruginoso-PESRM; I) ponto E2-PESRM. 
Segundo Marion \& Wimpey (2017) os fatores-chave para a perda de solo em trilhas são: comprimento da trilha, ângulo de alinhamento da inclinação, características de drenagem da trilha e a quantidade de rocha no substrato da trilha. O que se observa no padrão da trilha PI: nos períodos chuvosos o leito funciona também como drenagem $^{9}$. Nos trechos em que o alinhamento da inclinação da trilha é perpendicular às curvas de nível o potencial de degradação (e.g. erosão) aumenta para "muito alto" (idem). Já na trilha $\mathrm{CFa}$, com mais baixa altitude, há influência do regime de cheias repentinas do Ribeirão Mascates pelo acúmulo de água das chuvas nas cabeceiras ocasionando as "trombas d'água", "forma agressiva de impacto da água sobre o solo" (SALOMÃO \& IWASA, 1995) que de acordo com o substrato da trilha pode acelerar o processo erosivo pluvial, retirando a camada superficial do solo na parte da trilha, sazonalmente inundada. Não obstante a trilha $\mathrm{CFe}$, que é relativamente plana, não sofre com processos erosivos devido ao seu substrato ser constituído por couraça estruturada sobre itabiritos. Somente seu trecho inicial de acesso, entre o Centro de Visitantes e o topo de morro, com maior declividade, apresenta leito pavimentado por nódulos ferruginosos e fragmentos de itabirito, fruto da degradação da couraça e do itabirito a montante e seu transporte (fluxo gravitacional) fomentado pelo uso público (tráfego de veículos e de pedestres).

A associação da pedogênese com a morfogênese a partir da influência litológica é apontada por Tricart (1965), Gerrard (1995), Bigarella (2003) e Benites et al. (2007). Além dos últimos, que comprovaram nas serras do Espinhaço (onde parte da amostra ora em estudo se insere) e Mantiqueira, Vaschenko (2012) observou tal relação em trilhas do Parque Estadual Pico do Marumbi (PR). Na trilha PI, como os pontos E1, E4 e E5 estão sobre ou na transição de filitos/xistos do Grupo Sabará, observa-se maior compactação pela presença de granulometria mais fina do solo (silte e argila) do que em E2 e E3, mais arenosa por estarem sobre quartzitos do Grupo Itacolomi. Essas características de parte da trilha (textura e substrato) são observadas também entre E4 e o geossítio Pedra do Porco (OSTANELLO et al., 2013) cuja boa drenagem do Espodossolo encontrado na área, somada à textura e substrato, expôs perfil de Neossolo em barranco à jusante, acarretando na interdição do trecho original da trilha - pela insegurança ao visitante pela perda de solo do leito da trilha pela erosão.

\section{Considerações Finais}

A compactação e a erosão são processos naturais, que podem ser acelerados drasticamente pelo fator antrópico, ocasionando danos irreversíveis. No caso das áreas protegidas, as trilhas, em geral principais meios de acesso aos atrativos, ao perderem sua função de via segura (riscos aos transeuntes) podem representar perigo, podendo se transformar em danos ambientais: abióticos, como deslizamentos, causando a impossibilidade de se chegar ao atrativo; e bióticos, como supressão de vegetação e de fauna, com fechamento de trecho/trilha para recuperação.

A trilha Pico do Itacolomi, com maior altimetria dentre as três, e sobre quartzitos e xistos/filitos tem a maior erodibilidade, acredita-se devido à resistência do material de origem, podendo influenciar na composição e textura do solo, removendo e transportando o material mais friável. A trilha evidencia também a segunda maior compactação no leito da trilha, o que, somado ao seu fator de acessibilidade baixo (pelo comprimento e grau de dificuldade) repercute na necessidade de construção de mais estruturas, além das já existentes, tais como: passarela sobre áreas frágeis como a Lagoa Seca (E2 e P5 e P7) e trechos declivosos com solo arenoso sobre quartzitos (P6 a P8) por se localizarem, de acordo com o PM, em Zona Primitiva - de maior fragilidade; e corrimãos em aclives mais íngremes e argilosos (como o trecho em subida para o Pico do Itacolomi: E1 e P1 a P5), por se tornar escorregadio, aumentando os impactos pela erosão e risco aos caminhantes respectivamente.

No caso da trilha Campo Ferruginoso, constituída por fragmentos/nódulos ferruginosos em vertentes e substrato de couraça ferruginosa em altiplano, apresentou menor relação resistência do solo leito/margens e menor erosão. Esta resistência do substrato da trilha corrobora sua classificação como "zona intangível", preservando a fragilidade do seu geoecossistema de Campo Ferruginoso, rara em unidades de conservação. Logo, há uma ponte entre os resultados e o uso permitido para esse tipo de zoneamento: de "pesquisa científica, monitoramento e preservação". Assim, embora a trilha não apresentou alterações significativas de compactação e erosão em comparação com as outras trilhas, a fragilidade do campo rupestre hematítico é em si um valor da geodiversidade para prevenção da degradação do uso público, mesmo se geoturístico.

\footnotetext{
${ }^{9}$ A trilha não foi planejada conforme orientações de construção de trilhas, em ziguezague acompanhando curvas de nível e com estruturas como degraus, passarelas e contenções (USDA, 2010; TACÓN \& FIRMANI, 2010).
} 
A trilha Cachoeira da Farofa por sua vez, em sua maior parte constituída por substrato de sedimentos de aluvião sob solo arenoso e relevo relativamente plano, os poucos pontos de erosão (existentes e monitorados) e os predominantes de compactação no leito da trilha, podem ter impactos negativos aumentados pelo turismo. O zoneamento da trilha (de Uso Intensivo) contribui para avolumar a compactação e a erosão já observados.

A importância do Quadrilátero Ferrífero e da Serra do Espinhaço Meridional quanto à riqueza mineral de um lado e pressão antrópica (urbana e rural) de outro tem nos parques aqui analisados uma proteção dos geoecossistemas. $\mathrm{O}$ geoturismo pode ser considerado como estratégia de desenvolvimento sustentável, por meio de painéis explicativos dos processos de formação dos solos (pedogênese) e do relevo (morfogênese), que justificariam estruturas de contenção de erosão e passarelas sob trechos mais compactados das trilhas.

Apesar das limitações do presente trabalho - como mais pontos de medição da erosão, maior período de coleta de dados -, acredita-se que os dados obtidos possam subsidiar a revisão dos Planos de Manejo das UC. Assim, o presente estudo mostra a necessidade de um planejamento e monitoramento das trilhas, por meio de: continuidade dos estudos de impactos ambientais (e.g. compactação e erosão); de perfil do (geo)turista; de capacitação de guias de turismo e condutores dos parques; e de sinalização geoeducativa (e.g. painéis) nos pontos medidos, ora geossítios. Espera-se, com isso, uma potencialização do geoturismo, como fator de geoconservação.

\section{Agradecimentos}

Os autores agradecem à Universidade Federal de Ouro Preto pelo apoio; ao Instituto Estadual de Florestas e ao Instituto Chico Mendes de Conservação da Biodiversidade pelas licenças de pesquisa; às equipes dos Parques (Estadual do Itacolomi, Estadual Serra do Rola-Moça e Nacional da Serra do Cipó) pelo apoio logístico de campo; e aos revisores da Revista Brasileira de Geomorfologia pelas preciosas contribuições para melhoria do artigo.

\section{Referências Bibliográficas}

ABNT. (2008). NBR 15505-2. Turismo com atividades de caminhada. Parte 2: Classificação de percursos. Rio de Janeiro: Associação Brasileira de Normas Técnicas.
ALKMIM, F. F.; MARSHAK, S. (1998). Transamazonian Orogeny in Southern São Francisco Craton, Minas Gerais, Brazil: Evidence for Paleoproterozoic Collision and Collapse in the Quadrilátero Ferrífero. Precambriam Research, Amsterdam, v. 90, p. 29-58.

BALL, B. C.; CAMPBELL, D. J.; DOUGLAS, J. T.; HENSHALL, J. K.; O'SULLIVAN, M. F. (1997). Soil structural quality, compaction and land management. European Journal of Soil Science, v. 48, p. 593-601.

BENITES, V. M.; SCHAEFER, C. E. G. R.; SIMAS, F. N. B.; SANTOS, H. G. (2007). Soils associated with rock outcrops in the Brazilian mountain ranges Mantiqueira and Espinhaço. Revista Brasileira de Botânica, v. 30, n. 4, p. 569-577.

BERGER, A. R.; IAMS, W. J. (1996). Geoindicators: assessing rapid environmental change in Earth systems. Rotterdam: A. A. Balkema. 466p.

BERGER, A. R. (1997). Assessing rapid environmental change using geoindicators: Environmental Geology, v. 321, p. 36-44.

BIGARELLA, J. J. (2003). Estrutura e origem das paisagens Tropicais. v.3. Florianópolis: Ed. UFSC. 1.433p.

BRITO, A. L. (2015). A geodiversidade na unidade de conservação do Parque Nacional da Serra do Cipó (MG). Revista Espinhaço, v. 4, n. 2, p. 25-32.

BUCKLEY, R. (2004). Environmental impacts of ecotourism. Wallingford: Cabi, 416p.

CARVALHO FILHO, A.; CURI, N.; SHINZATO, E. (2010). Relações solo-paisagem no Quadrilátero Ferrífero em Minas Gerais. Pesq. Agrop. Bras., Brasília, v. 45, n. 8, p. 903-916.

CLARK, R. N.; STANKEY, G. H. (1979). The Recreation Opportunity Spectrum: a framework for planning, management, and research. Portland, USDA (United States Department of Agriculture), 32p.

COLE, D. N. (2004). Impacts of hiking and camping on soils and vegetation: a review. In BUCKLEY, R. (ed.) Environmental impacts of ecotourism. New York: CABI Publishing, p. 41-60.

CURI, N. (coord.). (1993). Vocabulário de ciência do solo. Campinas: Sociedade Brasileira de Ciência do Solo, 90p.

DORR, J. V. N. (1969). Physiographic, stratigraphic and structural development of the Quadrilátero Ferrífero, Minas Gerais, Brazil. U.S. Geological Survey Professional Paper, 641-A. U.S. Geological Survey. p. 1-110.

DUIKER, S. W. Effects of soil compaction. University Park, USA: Penn State College of Agricultural Sciences/United State Department of Agriculture, 12p. 
ESCHWEGE, W. L. [1833] (1979) Pluto brasiliensis. Belo Horizonte, Itatiaia, $528 \mathrm{p}$.

FELIPPE, M. F.; SILVA SOUZA, A. H.; MAGALHÃES JÚNIOR, A. P. (2012). Caracterização morfométrica dos compartimentos do relevo do Parque Nacional da Serra do Cipó, Serra do Espinhaço Meridional - Minas Gerais. Revista Espinhaço, v. 1, n. 1, p. 3-14.

FEOLA, E.; NUCCI, J. C.; SANTOS, L. J. C. (2008). Avaliação de impactos do uso público em uma trilha no Parque Estadual do Pico do Marumbi, Morretes - PR. Geografia, Rio Claro, v. 33 , n. 1, p. 157-175.

FERREIRA, A. C.; FIGUEIREDO, M. A.; SALVIO, G. M. M.; FERNANDES, B. H.; ROCHA, L. C. (2016). Estudos geoecológicos aplicados ao manejo da Trilha das Macaúbas na Floresta Nacional de Ritápolis - Minas Gerais. Caderno de Geografia, v. 26, n. 47, p. 714-736.

FIGUEIREDO, M. A.; BRITO, I. A.; TAKEUCHI, R. C.; ALMEIDA-ANDRADE, M.; ROCHA, C. T. V. (2010a). Compactação do solo como indicador pedogeomorfológico para erosão em trilhas de unidades de conservação: estudo de caso no Parque Nacional da Serra do Cipó, MG. Revista Geografia, Recife - UFPE, v. especial VIII SINAGEO, n. 3, p. 236-247.

FIGUEIREDO, M. A.; BRITO, I. A.; SANTANA, W. A.; ROCHA, C. T. V. (2010b). Compactação do solo em trilhas de unidades de conservação. Mercator, v. 9, n. 19, p. 165-174.

FIGUEIREDO, M. A.; FONSECA FILHO, R. E.; VARAJÃO, A. F. D. C. (2012). Qualidade do solo como geoindicador para o manejo de uma trilha no Parque Nacional da Serra do Cipó, MG, Brasil. Anuário do Instituto de Geociências - UFRJ, v. 35, n.1, p. 199-208.

FOLMANN, A. C.; PINTO, M. L. C.; GUIMARÃES, G. B. (2010). Trilhas interpretativas como instrumentos de geoturismo e geoconservação: caso da trilha do Salto São Jorge, Campos Gerais do Paraná. Geo UERJ, v. 2, n. 21, p. 1-19.

FONSECA FILHO, R. E. (2012). Qualidade do solo como um geoindicador de alterações ambientais no Parque Nacional da Serra do Cipó, MG. Dissertação (Mestrado em Ciências Naturais). Escola de Minas, Universidade Federal de Ouro Preto, Ouro Preto, MG. 121p.

FONSECA FILHO, R. E. (2017). Patrimônio Pedológico e fatores impactantes ambientais de uso público em Parques do Espinhaço Meridional. Tese (Doutorado em Ciências Naturais). Escola de Minas, Universidade Federal de Ouro Preto, Ouro Preto, MG. 411p.
FROSSARD, E.; BLUM, W. E. H.; WARKENTIN, B. P. (2006). Function of soils for human societies and the environment. London: The Geological Society. 208p.

GERRARD, J. (1995). Soil Geomorphology. An integration of Pedology and Geomorphology. London: Chapman \& Hall. 38p.

GOntiJo, A. H. F. (1993). O Relevo da Serra do Cipó - MG Espinhaço Meridional. Dissertação (Mestrado, em Geografia). Faculdade de Filosofia, Letras e Ciências Humanas, Universidade de São Paulo, São Paulo. 119p.

GRAY, M. (2004). Geodiversity. Valuing and conserving abiotic nature. Southern Gate, England: John Wiley and Sons, 508p.

GRAY, M. (2005). Geodiversity and Geoconservation: what, why and how? The George Wright Forum, v. 22, n. 3, p. 4-12.

GUALTIERI-PINTO, L.; OLIVEIRA, F. F.; ALMEIDAANDRADE, M.; PEDROSA, H. F.; SANTANA, W. A.; FIGUEIREDO, M. A. (2008). Atividade erosiva em trilhas de unidades de conservação: estudo de caso no Parque Nacional da Serra do Cipó, Minas Gerais, Brasil. e-Scientia, v. 1, n.1, p. 1-16.

GUERRA, A. J. T.; BOTELHO, R. G. M. (1996). Características e propriedades dos solos relevantes para os estudos pedológicos e análise dos processos erosivos. Anuário do Instituto de Geociências UFRJ, v. 19, p. 1-22.

HELGATH, S. F. (1975). Trail deterioration in the SelwayBitterroot Wilderness. Ogden: Usda/Forest Service. 17 p.

HOSE, T. (1995). Selling the Story of Britain's Stone. Environmental Interpretation, v. 10, n . 2, p. 16-17.

IBAMA. (2002). Roteiro Metodológico de Planejamento: Parque Nacional, Reserva Biológica e Estação Ecológica. Brasília: Instituto Brasileiro do Meio Ambiente. 136p.

ICMBIO. (2009). Plano de Manejo da Área de Proteção Ambiental Morro da Pedreira e do Parque Nacional da Serra do Cipó. Brasília: Instituto Chico Mendes de Conservação da Biodiversidade. $315 \mathrm{p}$.

IUGS (International Union of Geological Sciences). (2017a). Soil and sediment erosion. Disponível em http://www.lgt.lt/ geoin/doc.php?did=cl_soil. Acessado em 25 Ago. 2017a.

(2017b). Soil quality. Disponível em http://www.lgt. lt/geoin/doc.php?did=cl_soilq. Acessado em 25 Ago. 2017b.

KARLEN, D. L.; MAUS BACH J. W.; DORNA, R. G.; CLINE, R. F.; HARRIS, R. F.; SCHUMAN, G. E. (1997). Soil quality: a concept, definition and framework for evaluation (a guest editorial). Soil Science Society American Journal, n. 61, p. 4-10. 
KRIPPENDORF, J. (2000). Sociologia do turismo: para uma nova compreensão do lazer e das viagens. São Paulo: Aleph. 192 p.

LADEIRA, A. S. (2005). Avaliação de impactos da visitação, capacidade de carga turística e perfil dois visitantes do Parque Estadual do Ibitipoca, Lima Duarte - MG. Tese (Doutorado em Ciência Florestal). Centro de Ciências Agrárias, Universidade Federal de Viçosa. Viçosa, MG. 112p.

LAL, R. (1988). Erodibility and erosivity. In: LAL, R. et al. Soil erosion research methods. Washington: Soil and Water Conservation Society, p. 141-160.

LAL, R. (1990). Soil erosion in the Tropics: principles and management. London: McGraw-Hill, 580p.

LEONARD, R. E.; WHITNEY, A. M. (1977). Trail transect: a method for documenting trail changes. Broomall, USA: Usda, 10p.

LIDDLE, M. (1997). Recreation Ecology: the ecological impact of outdoor recreation and ecotourism. London: Chapman \& Hall, 639p.

MACHADO, M. F.; SILVA, S. F. (org.). (2010). Geodiversidade do Estado de Minas Gerais. Belo Horizonte: CPRM. 94p.

MAGRO, T. C. (1999). Impactos do uso público em uma trilha no planalto do Parque Nacional do Itatiaia. Tese (Doutorado em Ciências da Engenharia Ambiental). Escola de Engenharia de São Carlos, Universidade de São Paulo, São Carlos, SP. 151p.

MARION, J. L.; WIMPEY, J. (2017). Assessing the influence of sustainable trail design and maintenance on soil loss. Journal of Environmental Management, v. 189, p. 46-57.

MINAS GERAIS (2007a). Plano de manejo do Parque Estadual do Itacolomi. Belo Horizonte: Instituto Estadual de Florestas. 157p.

MINAS GERAIS. (2007b). Plano de Manejo do Parque Estadual da Serra do Rola Moça, incluindo a Estação Ecológica de Fechos. Encarte 3 - A unidade de conservação. Belo Horizonte: Biodiversitas. 213p.

MINAS GERAIS. (2012). Panorama da biodiversidade em Minas Gerais. Belo Horizonte: Instituto Estadual de Florestas. $286 \mathrm{p}$.

NASCIMENTO, M. A. L.; RUCHKYS, U.A.; MANTESSONETO, V. (2007). Geoturismo: um novo segmento do turismo no Brasil. Global Tourism, v. 3, n. 2, p. 1-24.

NORRISH, L. M. (2011). An exploration study into stakeholder perceptions of a proposed geotrail in the Perth Hills. Thesis (Doctorate in Business and Law). School of
Marketing, Tourism and Leisure, Edith Cowan University, Joondalup, Australia. 134p.

OLIVEIRA, L. H. M. (2016). Identificação e análise das unidades de paisagem do Parque Estadual da Serra do Rola-Moça e Estação Ecológica de Fechos, Quadrilátero Ferrífero - Minas Gerais. Dissertação (Mestrado em Análise e Modelagem de Sistemas Ambientais). Instituto de Geociências, Universidade Federal de Minas Gerais, Belo Horizonte. 44p.

OLIVEIRA, M. J. R.; FOGAÇA, A. C. C.; FONSECA, E. (1997). Geologia da Folha Baldim. In: GROSSI-SAD, J. H.; LOBATO, L. M.; PEDROSA-SOARES, A. C.; SOARESFILHO, B. S. (coord. eds.) Projeto Espinhaço. Belo Horizonte: COMIG, p. 2.437-2.531.

OSTANELLO, M. C. P.; DANDERFER FILHO, A.; CASTRO, P. T. A. (2013). Caracterização de Lugares de Interesse Geológico em trilhas geoturísticas no Parque Estadual do Itacolomi, Ouro Preto e Mariana, Minas Gerais. Geociências, São Paulo, Unesp, v. 32, n. 2, p. 286-297.

PELOSO, B. D. A. (2009). Classificação da vegetação do Parque Nacional da Serra do Cipó /MG e sua relação com variáveis morfométricas. Dissertação (Mestrado em Serviço de Informação e Documentação). Instituto Nacional de Pesquisas Espaciais, São José dos Campos, SP. 166p.

PICKERING, C. M.; HILL, W.; NEWSOME, D.; LEUNG, Y.F. (2010). Comparing hiking, mountain biking and horse riding impacts on vegetation and soils in Australia and the United States of America. Journal of Environmental Management, v. 91, p. 551-562.

PIJANOWSKI, B. C.; VILLANUEVA-RIVERA, L. J.; DUMYAHN, S. L.; FARINA, A.; KRAUSE, B. L.; NAPOLETANO, B. M.; GAGE, S. H.; PIERETTI, N. (2011). Soundscape ecology: the Science of sound in the landscape. BioScience, v. 61, n. 3, p. 203-216.

QIANG, S. H. I. (2006). The impact of tourism on soils in Zhangjiajie World Geopark. Journal of Forestry Research, v. 17, n. 2 , p. $167-170$.

RANGEL, L. A. (2014). O impacto da utilização de trilhas na Área de Proteção Ambiental de Cairuçu - Paraty - Rio de Janeiro. Dissertação (Mestrado em Geografia). Instituto de Geociências, Universidade Federal do Rio de Janeiro, Rio de Janeiro. 167p.

ROESER, H. M. P.; ROESER, P. A. (2010). O Quadrilátero Ferrífero-MG, Brasil: aspectos sobre sua história, seus recursos minerais e problemas ambientais relacionados. Geonomos, v. 18 , n. 1, p. $33-37$. 
ROSS, J. L. S. (1996). Geomorfologia aplicada aos EIAs-RIMAs. In: CUNHA, S. B.; GUERRA, A. J. T. (ed.) Geomorfologia e meio ambiente. Rio de Janeiro: Bertrand Brasil, p. 291-337.

RUCHKYS, U. A. (2007). Patrimônio geológico e geoconservação no Quadrilátero Ferrífero, Minas Gerais: potencial para criação de um geoparque da UNESCO. Tese (Doutorado em Geologia). Instituto de Geociências, Universidade Federal de Minas Gerais, Belo Horizonte. 211p.

SAADI, A. (1995). A geomorfologia da Serra do Espinhaço em Minas Gerais e de suas margens. Geonomos, v. 3, n. 1, p. 41-63.

SAINT-HILAIRE, A. [1830] (2015). Viagens pelas províncias do Rio de Janeiro e Minas Gerais. Belo Horizonte: Ed. Itatiaia. $378 \mathrm{p}$.

SALOMÃO, F. X. T.; IWASA, O. Y. (1995). Erosão e a ocupação rural e urbana. In: BITAR, O.Y. (org.) Curso de Geologia Aplicada ao Meio Ambiente. São Paulo: ABGE/IPT, p. 31-57.

SARAIVA, A. C. R. (2011). Impactos aos atributos físicos do solo em trilhas ocasionados pelo ecoturismo em Ubatuba-SP. Revista Univap, São José dos Campos-SP, v. 17, n. 29, p. 32-40.

SENA, I. S.; TEIXEIRA, H. W.; FIGUEIREDO, M. A.; ROCHA, L. C. (2014). Degradação dos solos ao longo de uma trilha de destino a atrativos do Monumento Geoturístico Serra de São José, Tiradentes, Minas Gerais, Brasil. Geonomos, v. 22, n. 2, p. 70-76.

SHINZATO, E.; CARVALHO FILHO, A.; TEIXEIRA, W. G. (2008). Solos Tropicais. In: SILVA, C. R. (ed.). Geodiversidade do Brasil. Conhecer o passado para entender o presente e prever o futuro. Rio de Janeiro, Serviço Geológico do Brasil (CPRM). p. 122-134.

SILVA, G. L.; FREITAS, M. A.; SILVEIRA, V. D. (2007). Geologia da região centro-oeste do Parque Nacional da Serra do Cipó: municípios de Jaboticatubas e de Santana do Riacho, MG. Trabalho de Graduação (Bacharelado em Geologia). Instituto de Geociências, Universidade Federal de Minas Gerais, Belo Horizonte. 46p.

SOLOTEST. (2011). Manual do penetrômetros para solos, com anel dinamométrico. Bela Vista, SP: Solotest. $3 p$

STANKEY, G. H.; COLE, D. N.; LUCAS, R. C.; PETERSEN, M. E.; FRISSELL, S. S. (1985). The Limits of Acceptable Change (LAC) System for Wilderness Planning. Odgen: Forest Service/USDA. 37p.

SWARBROOKE, J. (2002). Turismo Sustentável: conceitos e impacto ambiental. v. 1. 3. ed. São Paulo: Aleph.

TACÓN, A.; FIRMANI, C. (2004). Manual de senderos y uso público. Valdivia: Cipma (Proyecto Ecorregion Valdiviana), 23p.

THORNES, J. B. (2011). The Ecology of Erosion. Geography, v.70, p. 222-235.

TRICART, J. (1965). Morphogenese et pedogenese. I. Approche methodologique, geomorphologie et pedologie. Science du Sol, v. 1, p. $69-85$.

USDA. (2004). Trail construction and maintenance notebook. Washington: Usda, $141 \mathrm{p}$.

VARAJÃO, C. A. C. (1988). Estudo comparativo das jazidas de bauxita do Quadrilátero Ferrífero, MG. Dissertação (Mestrado em Geologia). Instituto de Geociências, Universidade de São Paulo, São Paulo. 232p.

VASCHENKO, Y. (2012). Fatores que influenciam a erosão hídrica nas trilhas do Parque Estadual Pico do Marumbi - PR. Tese (Doutorado em Engenharia Florestal). Centro de Ciências Florestais e da Madeira, Universidade Federal do Paraná, Curitiba. 180p.

VINCENT, R. C. (2004). Florística, fitossociologia e relações entre a vegetação e o solo em áreas de Campos Ferruginosos no Quadrilátero Ferrífero, Minas Gerais. Tese (Doutorado em Botânica). Instituto de Botânica, Universidade de São Paulo, São Paulo. 145p.

WILSON, E. O. (ed) (1988). Biodiversity. Washington: National Academy Press, 521p.

WOLTERS, T. M. (1989). Tourism carrying capacity. Tourism and the Environment, v. 7, n. 1, p. 30-36. 